\title{
A prospective observation on nutrition support in adult patients with severe burns
}

\author{
Fengmei Guo ${ }^{1}$, Hua Zhou ${ }^{2}$, Jian $\mathrm{Wu}^{3}$, Yingzi Huang ${ }^{1}$, Guozhong $\mathrm{Lv}^{4}$, Yunfu Wu ${ }^{3}$, Hongsheng Zhao ${ }^{5}$ \\ Jun Jin ${ }^{6}$, Fuli Zhao ${ }^{3}$, Lijun Liu ${ }^{7}$, Wenming Liu ${ }^{8}$, Yi Yang ${ }^{1}$, Yuan Xu ${ }^{2} \dagger$ and Haibo Qiu ${ }^{1 *}+$ \\ ${ }^{1}$ Nanjing Zhongda Hospital, Southeastern University School of Medicine, Nanjing 210009, People's Republic of China \\ ${ }^{2}$ Beijing Tsinghua Changgung Hospital, Beijing 102218, People's Republic of China \\ ${ }^{3}$ Suzhou Municipal Hospital, Suzhou 215000, People's Republic of China \\ ${ }^{4}$ Wu xi Third People's Hospital, Wuxi 214041, People's Republic of China \\ ${ }^{5}$ First Affiliated Hospital of Medical School of Nantong University, Nantong 226021, People's Republic of China \\ ${ }^{6}$ First Affiliated Hospital of Suzhou University, Suzhou 215006, People's Republic of China \\ ${ }^{7}$ Second Affiliated Hospital of Suzhou University, Suzhou 215004, People's Republic of China \\ ${ }^{8}$ Changzhou Second People's Hospital, Changzhou 213003, People's Republic of China
}

(Submitted 14 June 2018 - Final revision received 31 October 2018 - Accepted 27 January 2019)

\section{Abstract}

Nutrition therapy is considered an important treatment of burn patients. The aim of the study was to delineate the nutritional support in severe burn patients and to investigate association between nutritional practice and clinical outcomes. Severe burn patients were enrolled ( $n$ 100). In $90 \%$ of the cases, the burn injury covered above $70 \%$ of the total body surface area. Mean interval from injury to nutrition start was 2.4 (sD 1-1) d. Sixty-seven patients were initiated with enteral nutrition (EN) with a median time of $1 \mathrm{~d}$ from injury to first feed. Twenty-two patients began with parenteral nutrition (PN). During the study, thirty-two patients developed EN intolerance. Patients received an average of about $70 \%$ of prescribed energy and protein. Patients with EN providing $<30 \%$ energy had significantly higher 28 - $\mathrm{d}$ and in-hospital mortality than patients with EN providing more than $30 \%$ of energy. Mortality at $28 \mathrm{~d}$ was $11 \%$ and in-hospital mortality was $45 \%$. Multiple regression analysis demonstrated that EN providing $<30 \%$ energy and septic shock were independent risk factors for 28 - $\mathrm{d}$ prognosis. EN could be initiated early in severe burn patients. Majority patients needed PN supplementation for energy requirement and EN feeding intolerance. Postpyloric feeding is more efficient than gastric feeding in EN tolerance and energy supplement. It is difficult for severe burn patients to obtain enough feeding, especially in the early stage of the disease. More than 2 weeks of underfeeding is harmful to recovery.

\section{Key words: Severe burns: Enternal nutrition: Parenteral nutrition: Clinical outcomes}

Severe burn remains a major healthcare problem throughout the world ${ }^{(1,2)}$. It is accepted that patients with severe burn injuries are characterised by an intense inflammatory response, a strong oxidative stress and a prolonged hypermetabolism and catabolic response, and they are proportional to the depth and area of burn injury ${ }^{(3-6)}$. Nutrition therapy is recognised as one of the most significant treatment aspects for burn patients, on the grounds of physiological rationale; nutrition guideline was designed specifically for burn patients ${ }^{(7)}$. However, the guideline was largely based on studies with limited sample sizes, with variable qualities or expert opinions ${ }^{(8-10)}$.

Nutritional therapy is preferentially delivered via the enteral route, with a recommended early start in the critically $\mathrm{ill}^{(7)}$. However, enteral feeding is often poorly tolerated in critically ill patients. The gastrointestinal tract intolerance syndrome seems to occur in $10-52 \%$ of patients who receive gastric feeding. Through previous studies over the past decade ${ }^{(11,12)}$, the prevalence of 'feeding intolerance' and fasting in severe burn patients may be the chief factors resulting in inadequate enteral nutrition (EN) in critically ill patients ${ }^{(13)}$. Both risk factors appear to be particularly prevalent in severe burn injury patients ${ }^{(14)}$, suggesting that energy and protein delivery may be insufficient in these patients.

There are limited data relating the actual nutritional practices in patients with severe burn injury. In this study, we aim to delineate the nutrition support in adult patients with severe burns in a massive explosion in China, thus to investigate the association between nutritional practice and clinical outcomes.

Abbreviations: EN, enteral nutrition; PN, parenteral nutrition.

* Corresponding author: H. Qiu, fax +86 25 83272011, email haiboq2000@163.com

$\dagger$ Yuan Xu and Haibo Qiu contributed equally to this paper. 
Table 1. Characteristics of the patients at baseline $(n 100)^{\star}$

(Mean values and standard deviations; medians and interquartile ranges (IQR); numbers and percentages)

\begin{tabular}{|c|c|c|}
\hline Characteristics & Mean & SD \\
\hline \multicolumn{3}{|l|}{ Male patients } \\
\hline$n$ & \multicolumn{2}{|c|}{55} \\
\hline$\%$ & \multicolumn{2}{|c|}{$55 \cdot 0$} \\
\hline \multicolumn{3}{|l|}{ Age (years) } \\
\hline Median & \multirow{2}{*}{\multicolumn{2}{|c|}{$\begin{array}{c}35 \cdot 6 \\
28-43\end{array}$}} \\
\hline IQR & & \\
\hline Height $(\mathrm{cm})$ & $165 \cdot 0$ & $6 \cdot 2$ \\
\hline Weight (kg) & $65 \cdot 8$ & 21.5 \\
\hline BMI $\left(\mathrm{kg} / \mathrm{m}^{2}\right)$ & $21 \cdot 6$ & 1.5 \\
\hline $\operatorname{BMR}(\mathrm{kJ} / \mathrm{d})$ & $5629 \cdot 6$ & $694 \cdot 1$ \\
\hline APACHE II score at admission to ICU & 12.5 & 4.5 \\
\hline \multicolumn{3}{|l|}{ Burned BSA (\%) } \\
\hline \multicolumn{3}{|l|}{ Global } \\
\hline Median & \multirow{2}{*}{\multicolumn{2}{|c|}{$\begin{array}{c}94.5 \\
90-98\end{array}$}} \\
\hline IQR & & \\
\hline \multicolumn{3}{|l|}{ Third degree } \\
\hline Median & \multicolumn{2}{|c|}{88} \\
\hline IQR & \multicolumn{2}{|c|}{$76-95$} \\
\hline \multicolumn{3}{|l|}{ Patients with inhalation injury } \\
\hline$n$ & \multicolumn{2}{|c|}{100} \\
\hline$\%$ & \multicolumn{2}{|c|}{100} \\
\hline Patients with malnutrition & \multicolumn{2}{|c|}{0} \\
\hline \multicolumn{3}{|l|}{ Admission value } \\
\hline Mean prealbumin (mg/l) & $119 \cdot 0$ & $25 \cdot 6$ \\
\hline Leucocytes $\left(\right.$ cells $\left./ \mathrm{m}^{3}\right)$ & $10 \cdot 3$ & 3.6 \\
\hline Serum glucose $(\mathrm{mmol} / \mathrm{l})$ & $9 \cdot 1$ & 1.6 \\
\hline Serum creatinine $(\mu \mathrm{mol} / /)$ & $46 \cdot 8$ & $5 \cdot 3$ \\
\hline
\end{tabular}

\section{Methods}

\section{Data sources and study patients}

On 2 August 2014, a provincial network was set up in Jiangsu by the provincial government, to organise, coordinate and guide the management of the burn patients. The clinical treatment group included the Jiangsu Provincial Health Department and an expert panel from the departments of burn and critical care medicine.

This prospective, observational, multicentre trial was conducted in intensive care unit (ICU) of seven hospitals. Burn patients in a massive explore in Kunshan, Jiangsu Province, China, on 2 August 2014 were included. Patient inclusion criteria were admission on day 1 of burn injury, older than 18 years of age and expected to survive more than $48 \mathrm{~h}$. Feeding protocol recommended by the expert panel was based on the European Society for Clinical Nutrition and Metabolism (ESPEN) guideline, and according to the guideline EN should be started as early as possible, gastric feeding via a nasogastric tube was the first choice, post-pyloric feeding was performed in patients developing gastric feeding intolerance, parenteral nutrition (PN) was suggested when EN was not available or EN intolerance happened. The correct gastric position of the feeding tube was checked by radiography. Energy target was set according to Toronto equation, and the protein intake had been considered to be around $2 \mathrm{~g} / \mathrm{kg}$ per $\mathrm{d}$ based on the ESPEN guideline. The above feeding strategy was implemented by the attending physician based on the specific circumstances of the patients. Daily data were recorded for a maximum of $28 \mathrm{~d}$ for each patient. Patients survived in hospital at the 28th day or being discharged before $28 \mathrm{~d}$ were considered to be survivors. The study was approved by the Ethics Committee of Southeast University affiliated Zhongda Hospital (reference number: 2014ZDSYLL116.1). All participating hospitals accepted the central ethics committee review. The study complied with the Declaration of Helsinki regarding ethical principles of human subject research and the relevant ethical requirements of the International Conference on Harmonisation/Good Clinical Practice guidance and national regulations. Written informed consents were provided by the participants or their legal representatives.

Burn wounds of all the patients were treated in a uniform fashion with regard to excisional and grafting therapy. Patients received urgent and periodic surgeries to remove all charred tissues and graft which involves a combination of autograft, homograft or artificial skin.

A case report form (CRF) was completed for each patient by his/her physician as soon as possible after inclusion in the study. The CRF included the following items: Acute Physiology and Chronic Health Evaluation (APACHE II) scores based on the worst values obtained within $24 \mathrm{~h}$ after the onset of the injury; laboratory test values including blood leucocytes, prealbumin, serum glucose and serum creatinine at admission, burn size and depth of burn; the route, timing and amount of nutrition support; the daily energy and protein intake, and energy requirement at the same time according to the Toronto equation $^{(7)}$ feeding intolerance or other adverse events in feeding; the occurrence of infection or septic shock; and clinical outcomes. Feeding intolerance was defined as gastric residual volume (GRV) from 150 to $500 \mathrm{ml}$ in two occasions between $6 \mathrm{~h}$, or GRV $>500 \mathrm{ml}$ in one measurement or when vomiting, abdominal distention or diarrhoea occurred. Postpyloric feeding was performed in patients developing gastric feeding intolerance. Septic shock was defined as persistent hypotension induced by infection, despite adequate fluid resuscitation. Infection was diagnosed by positive culture of pathogenic microorganisms in suspected infection sites. The main infection sites were burn wound, blood and lung. All the septic shock patients were treated with targeted antibiotics. Attributable mortality rate was evaluated using the definition of Montgomery et $a l^{(15)}$ for irreversible organ dysfunction.

\section{Statistics}

Continuous variables were summarised as either mean and standard deviations or medians with interquartile ranges. For categorical variables, the frequency and percentage of patients in each category were calculated. $T$ test, $\chi^{2}$ test or Fisher exact test was used to compare the categorical variables. Means between groups were compared via Mann-Whitney $U$ test. The differences in prognostic factors in surviving and non-surviving patients were evaluated with Fisher exact tests. Multiple logistic regression analysis was used to identify independent predictors of mortality. All tests were two tailed, and $P<0.05$ in the final 
Table 2. Clinical management, feeding adverse events and outcomes in the 100 patients

(Number and percentage; median and interquartile range (IQR); mean value and standard deviation)

\begin{tabular}{|c|c|c|c|}
\hline Characteristics & $n$ & & $\%$ \\
\hline \multicolumn{4}{|l|}{ No. of days to initiation of nutritional support } \\
\hline Median & \multicolumn{3}{|c|}{2} \\
\hline IQR & \multicolumn{3}{|c|}{$1-3$} \\
\hline Nutritional support within $72 \mathrm{~h}$ after burn injury & 89 & & 89 \\
\hline $\begin{array}{l}\text { Feeding initiated by the enteral route only } \\
\text { Days to starting nutrition }\end{array}$ & \multicolumn{2}{|c|}{ Days to starting nutrition } & $29 \cdot 2$ \\
\hline Median & \multicolumn{3}{|c|}{1} \\
\hline IQR & \multicolumn{3}{|c|}{$1-3$} \\
\hline \multicolumn{4}{|l|}{ Days to starting nutrition } \\
\hline Median & \multicolumn{3}{|c|}{2} \\
\hline IQR & \multicolumn{3}{|c|}{$2-3$} \\
\hline $\begin{array}{l}\text { Feeding initiated by the enteral and } \\
\text { parenteral route }\end{array}$ & 41 & & $46 \cdot 1$ \\
\hline \multicolumn{4}{|l|}{ Days to starting nutrition } \\
\hline Median & \multicolumn{3}{|c|}{2} \\
\hline IQR & \multicolumn{3}{|c|}{$2-3$} \\
\hline $\begin{array}{l}\text { Initiated exclusive oral feeding during } 30 \mathrm{~d} \text { after } \\
\text { injury }\end{array}$ & 4 & & 4 \\
\hline Mean time to starting exclusive oral feeding (d) & & 25 & \\
\hline \multicolumn{4}{|l|}{ Nutritional route } \\
\hline $\begin{array}{l}\text { Only a gastric tube for the duration of } \\
\text { admission }\end{array}$ & 72 & & 72 \\
\hline $\begin{array}{l}\text { Gastric followed by placement of a } \\
\text { post-pyloric tube }\end{array}$ & 21 & & 21 \\
\hline $\begin{array}{l}\text { Gastric tube and post-pyloric tube when had } \\
\text { feeding initiated }\end{array}$ & 7 & & 7 \\
\hline $\begin{array}{l}\text { Patients receiving prokinetic drug during } \\
\text { intervention period }\end{array}$ & 90 & & 90 \\
\hline \multicolumn{4}{|l|}{ Prealbumin (mg/l) } \\
\hline \multicolumn{4}{|l|}{ Day 14} \\
\hline Mean & \multicolumn{3}{|c|}{$162 \cdot 4$} \\
\hline SD & \multicolumn{3}{|c|}{$52 \cdot 1$} \\
\hline \multicolumn{4}{|l|}{ Day 28} \\
\hline Mean & \multicolumn{3}{|c|}{$158 \cdot 3$} \\
\hline SD & & $39 \cdot 8$ & \\
\hline $\begin{array}{l}\text { Blood glucose during intervention period } \\
(\mathrm{mmo} / \mathrm{l})\end{array}$ & & & \\
\hline Daily lowest & & & \\
\hline Mean & & $5 \cdot 3$ & \\
\hline SD & & $3 \cdot 2$ & \\
\hline Daily highest & & & \\
\hline Mean & & $12 \cdot 5$ & \\
\hline SD & & $7 \cdot 8$ & \\
\hline $\begin{array}{l}\text { Patients receiving sustained insulin therapy - } \\
\text { no./total no. (\%) }\end{array}$ & 18 & & 18 \\
\hline No. of days on mechanical ventilation & & & \\
\hline Median & & 12 & \\
\hline IQR & & $8-18$ & \\
\hline Feeding adverse events & & & \\
\hline Gastric residual volumes or vomiting & 21 & & 21 \\
\hline Abdominal distention & 9 & & 9 \\
\hline Diarrhoea & 6 & & 6 \\
\hline Regurgitation or aspiration & 13 & & 13 \\
\hline Elevated liver enzymes & 12 & & 12 \\
\hline Jaundice & 8 & & 8 \\
\hline Electrolyte disturbance & 16 & & 16 \\
\hline Upper gastrointestinal haemorrhage & 6 & & 6 \\
\hline Interruptions to nutritional delivery & & & \\
\hline Interruptions to nutritional delivery & 95 & & 95 \\
\hline Days of interruption & & & \\
\hline Median & & 3 & \\
\hline IQR & & $2-5$ & \\
\hline Number of operations in the first month & & & \\
\hline Median & & 3 & \\
\hline IQR & & $2-4$ & \\
\hline
\end{tabular}

Table 2. Continued

\begin{tabular}{|c|c|c|}
\hline Characteristics & $n$ & $\%$ \\
\hline Use of growth hormone & 36 & 36 \\
\hline Use of $n-3$ fatty acids & 33 & 33 \\
\hline Use of glutamine & 72 & 72 \\
\hline Acid-suppressive medication & 91 & 91 \\
\hline \multicolumn{3}{|c|}{ Outcomes } \\
\hline \multicolumn{3}{|c|}{ Days between illness onset and death } \\
\hline Median & \multirow{2}{*}{\multicolumn{2}{|c|}{$\begin{array}{c}21 \\
4-26\end{array}$}} \\
\hline IQR & & \\
\hline Mortality in the ICU, no./total no. & $11 / 100$ & 11 \\
\hline Mortality at $14 \mathrm{~d}$, no./total no. & $6 / 100$ & 6 \\
\hline Mortality at $28 \mathrm{~d}$, no./total no. & $11 / 100$ & 11 \\
\hline Mortality in-hospital, no./total no. & $45 / 100$ & 45 \\
\hline \multicolumn{3}{|l|}{ Attributable mortality } \\
\hline Severe burn injury, no./total no. & $3 / 45$ & $6 \cdot 7$ \\
\hline Septic shock, no./total no. & $42 / 45$ & $93 \cdot 3$ \\
\hline
\end{tabular}

analysis was considered statistically significant. All analyses were carried out using SPSS software for Windows (release 16.0).

\section{Results}

\section{Demographic and clinical characteristics}

One hundred patients from seven hospitals were enrolled, contributing a total of 945 study days. All the patients were admitted to ICU. Most of the patients had extremely severe burns. In all, ninety patients had burn injuries above $70 \%$ of the total body surface area (TBSA), and seventy-seven patients had above $90 \%$ TBSA burn. Ninety-two patients had a third-degree burn covering more than $50 \%$ TBSA. All the patients had smoke inhalation injuries and received mechanical ventilation. The median number of days on mechanical ventilation was 12 . Mean APACHE II score at admission was 12.5 (SD 4.5). The level of prealbumin decreased significantly at admission. None had co-morbidities and all were healthy before injury. Baseline characteristics of the patients are shown in Table 1.

\section{Nutrition delivery}

Overall, eighty-nine patients received nutritional support within $72 \mathrm{~h}$ after burn injury. Of these, sixty-seven patients initiated with EN and twenty-two patients started with PN. For all patients, median to initiation of nutritional support was $2 \mathrm{~d}$, and for patients feeding was initiated only through the enteral route, the median time was $1 \mathrm{~d}$. Ten patients received oral nutrition within $28 \mathrm{~d}$ of observation. Patients with EN were more likely than those with PN to initiate early oral nutrition. Four patients took oral nutrition exclusively with a mean starting time for exclusive oral nutrition of 24.8 (SD 4.6) d. Prealbumin levels were lower than normal at days 14 and 28 (Table 2).

The daily energy content, fat, carbohydrate and amino acid intake up to day 28 are delineated in Fig. 1. The mean energy intake was $11.4 \mathrm{kcal} / \mathrm{kg}(47.7 \mathrm{~kJ} / \mathrm{kg})$ of actual body weight on the 1 st day, which gradually increased to $33.8 \mathrm{kcal} / \mathrm{kg}(141.4 \mathrm{~kJ} / \mathrm{kg})$ of actual body weight per $\mathrm{d}$ within the first week. After 2 weeks, 
Nutritional support for severely burned patients
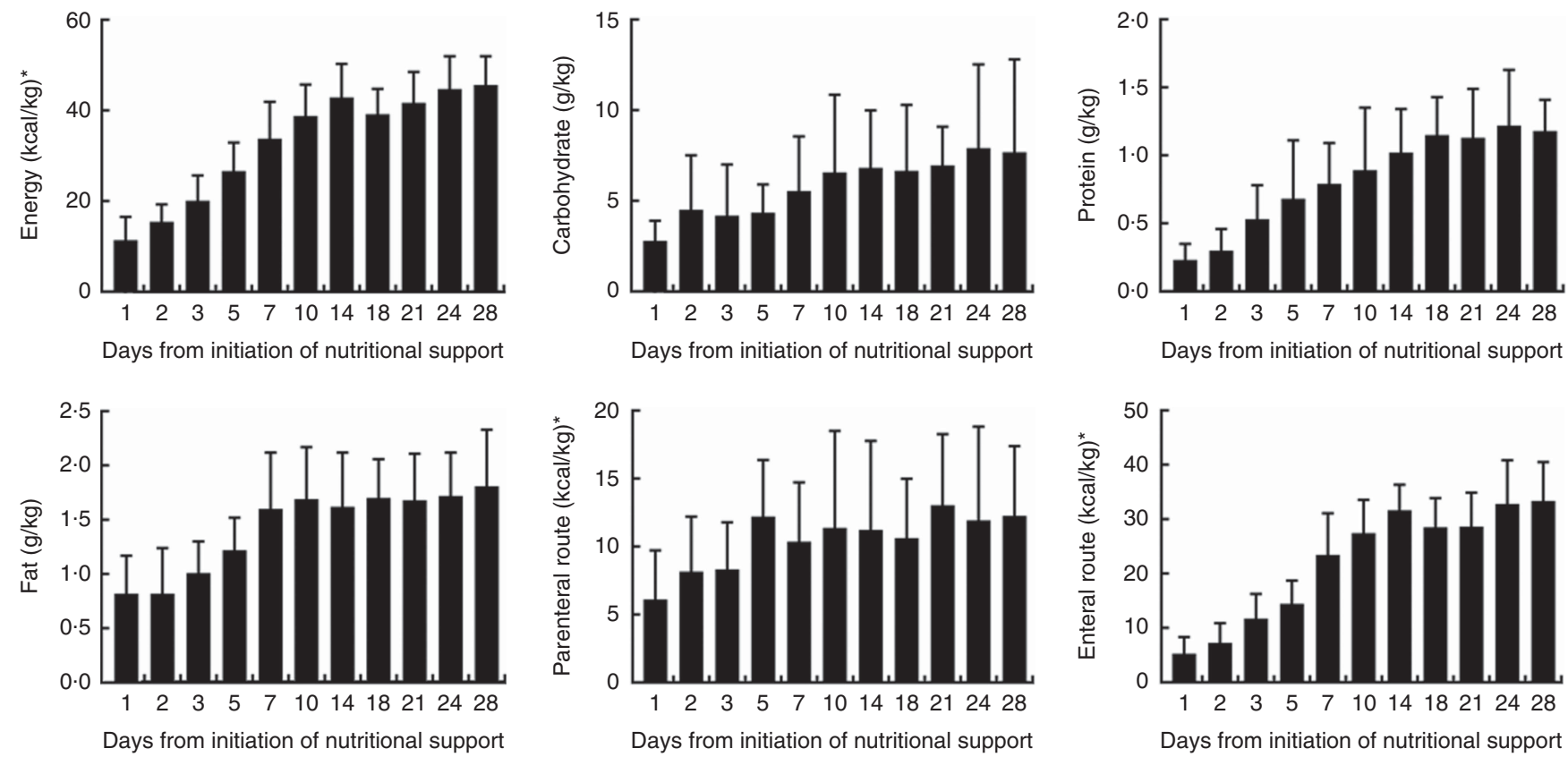

Fig. 1. Energy and protein delivered as a percentage of prescribed values regardless of the route. * To convert kcal to kJ, multiply by $4 \cdot 184$.

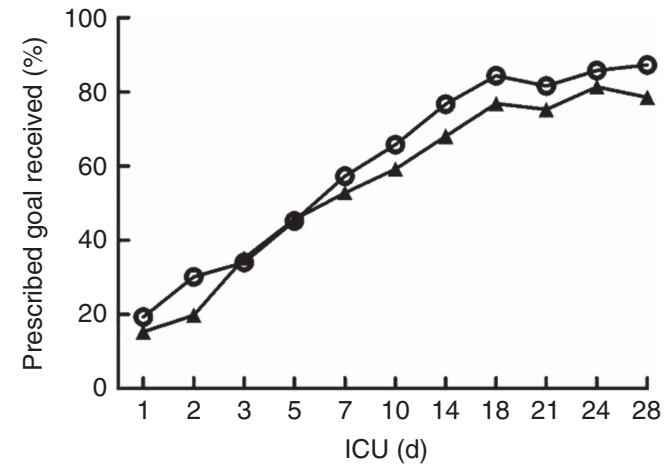

Fig. 2. Energy ( $(-)$ and protein $(\neg-)$ delivered as a percentage of prescribed values regardless of the route. ICU, intensive care unit.

the mean energy supply reached about $40 \cdot 0 \mathrm{kcal} / \mathrm{kg}(167 \cdot 4 \mathrm{~kJ} / \mathrm{kg})$ of actual body weight per $\mathrm{d}$ until the fourth week. It was the same as the protein supply. Compared with energy requirement calculated by the Toronto formula at the same time, the patients received about $70 \%$ of their prescribed energy and protein requirements by nutrition therapy after 2 weeks during our observation (Fig. 2). The mean energy deficit up to day 28 for all patients was $1173 \mathrm{kcal} / \mathrm{d}(4908 \mathrm{~kJ} / \mathrm{kg})$, with a mean protein deficit up to day 28 of $57 \mathrm{~g} / \mathrm{d}$. Higher energy and protein deficiency were found in patients with gastric feeding $(n$ 72) compared with those with post-pyloric feeding $(n$ 28) (1368 $v$. $979 \mathrm{kcal} / \mathrm{d}(5724$ v. $4096 \mathrm{~kJ} / \mathrm{d}), P=0.034 ; 68.3$ v. $46 \cdot 1 \mathrm{~g} / \mathrm{d}$, $P=0.026$ ) (Fig. 3(a))

Eleven patients received only total EN feeding in the study, the remaining eighty-nine patients were fed by EN combined with PN. Of all the patients, forty-seven patients received total protein formula, while fifty-three were fed by short polypeptide formula. No difference was seen in total energy and protein intake between patients with $\mathrm{EN}$ and patients with EN combined with PN. Compared with the EN feeding, patients in the EN combined with PN group were more severely injured. No differences could be noted in the severity of injury or energy and protein intake among patients with different EN:PN ratio; higher incidence of nutrition intolerance was found in patients with EN providing $<60 \%$ of the prescribed energy content compared to those with EN providing more than $60 \%$ prescribed energy content. The patients with EN providing more than $30 \%$ of energy content had lower incidence of haemodynamic instability $(27 \cdot 3 v .72 \cdot 7 \%)$ and 28 -d mortality $(7 \cdot 3 v$. $36 \cdot 4 \%$ ), and in-hospital mortality (38.8 v. 86.3\%) compared with patients with EN providing energy content $<30 \%$ (Table 3).

The majority of patients ( $n$ 95) had interruptions to their feeding during the $28 \mathrm{~d}$. The median duration of interruption was $3 \mathrm{~d}$. Sixteen patients had interruptions even more than $5 \mathrm{~d}$. Fasting for procedures resulted in feeding interruption. The other main contributing factors included haemodynamic abnormality, gastrointestinal access displaced and EN feeding intolerance.

\section{Adverse events}

Thirty-two patients developed feeding intolerance during the study, with the mean duration of 4.7 (sD 3.5) d. The most common clinical manifestations were higher GRV or vomiting ( $n$ 21), abdominal distension occurred ( $n$ 9) and diarrhoea ( $n$ 6). Enteral refeeding was performed in twenty-one patients with post-pyloric tube. Features of nutrition support with or without feeding intolerance were summarised in Table 4. Overfeeding, total protein formula and haemodynamic instablitity seemed to be the main reasons for feeding intolerance. In patients with EN intolerance, more patients had hyperglycosaemia. There was no significant difference in feeding route and 
(a)
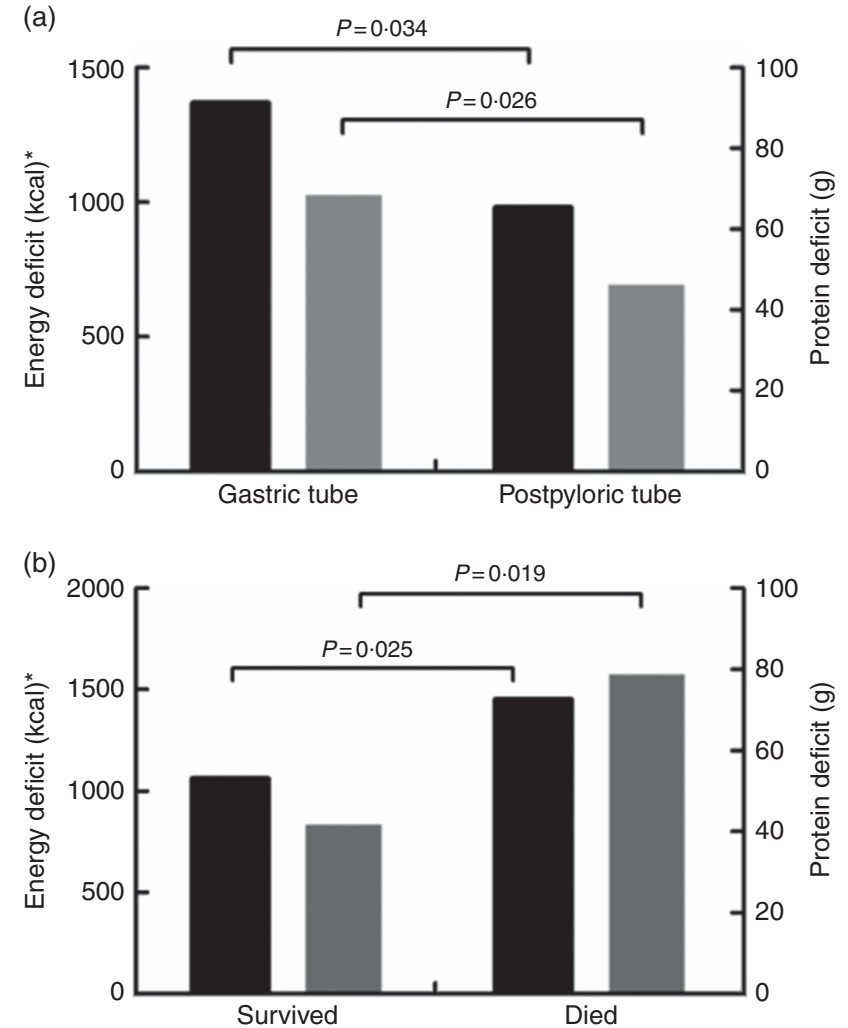

Fig. 3. (a) Energy ( $\square$ ) and protein $(\square)$ deficits in relation to nutrition routes from days 1 to 28. (b) Energy and protein deficits in relation to prognosis from days 1 to 28 . * To convert kcal to $\mathrm{kJ}$, multiply by $4 \cdot 184$.

feeding type between patients with EN tolerance and intolerance. Other main adverse events included blood glucose fluctuations and hepatic enzyme elevation. Forty-eight patients had at least once a fasting blood glucose $>10 \mathrm{mmol} / \mathrm{l}$, six patients experienced hypoglycaemic episodes (blood glucose $<3.5 \mathrm{mmol} / \mathrm{l}$ ), twelve patients had elevated liver enzymes and eight patients had jaundice.

\section{Clinical outcomes}

Eleven patients died, and no patients were discharged $28 \mathrm{~d}$ after admission. The clinical outcomes are summarised in Table 2. Mortality rate at day 14 was $6 \%$ (6 of 100), which increased to $11 \%$ (11 of 100 ) at day 28 , and in-hospital mortality was $45 \%$. The cause of death was septic shock. Three patients died within $3 \mathrm{~d}$ after admission.

The patients who were fed by EN providing $<30 \%$ of energy had significantly higher mortality than those who fed by EN providing more than $30 \%$ of energy $(P=0.001)$. Severity of burn injury, energy and protein intake were all similar in these patients. Higher energy and protein deficiency were found in survival patients compared to dead patients (Fig. 3(b)). Compared with survivors, non-survivors received more surgeries, with an energy intake lower than $30 \mathrm{kcal} / \mathrm{kg}(126 \mathrm{~kJ} / \mathrm{kg})$ of actual body weight per $\mathrm{d}$ at $14 \mathrm{~d}$ after injury. In addition to the incidence of energy and protein deficits, EN intolerance and septic shock were significantly more frequent in the nonsurvivors (Table 5). Considering all these prognostic factors

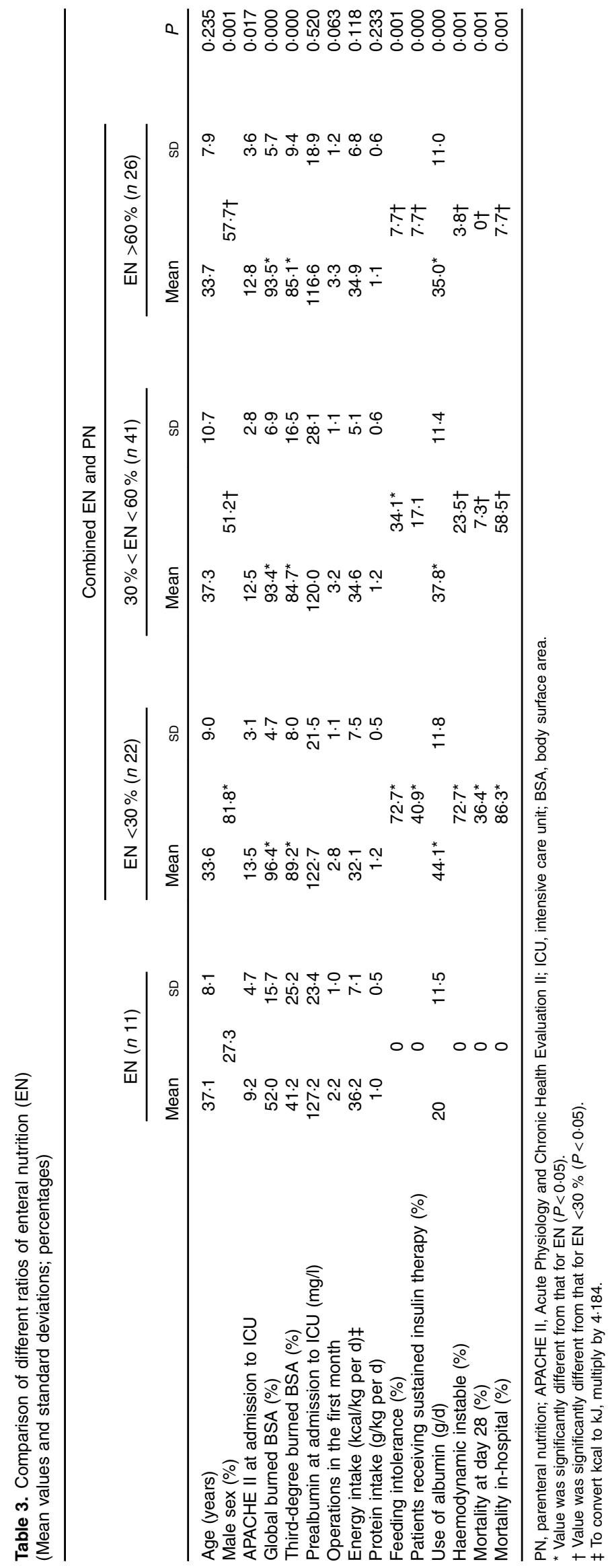


Table 4. Nutrition characteristics with and without enteral nutrition (EN) intolerance (n 100)

\begin{tabular}{lccc}
\hline & EN intolerance & EN tolerance \\
\hline Formula total protein/short polypeptide & $20 / 12$ & $27 / 41$ & 0.033 \\
Feeding route gastric/post-pyloric & $25 / 7$ & $47 / 21$ & 0.349 \\
Feeding type continuous feeding/bolus & $8 / 24$ & $29 / 39$ & 0.088 \\
EN intake per d (ml) $>1500 /<1500$ & $25 / 7$ & $39 / 29$ & 0.044 \\
Prokinetics, yes/no & $27 / 5$ & $63 / 5$ & $0 \cdot 198$ \\
Acid-suppressive medication, yes/no & $29 / 3$ & $62 / 6$ & 0.928 \\
Haemodynamic stable/instable & $13 / 19$ & $60 / 8$ & 0.000 \\
Mean blood glucose (mmol/l) $>10 /<10$ & $19 / 13$ & $26 / 42$ & 0.047 \\
\end{tabular}

Table 5. Prognostic factors in non-surviving and surviving burn injury patients ( $n$ 100)

\begin{tabular}{|c|c|c|c|}
\hline & Non-survivor & Survivor & $P$ \\
\hline Age $\leq 40$ years $/>40$ years & $9 / 2$ & $52 / 37$ & 0.133 \\
\hline Sex (male/female) & $7 / 4$ & $48 / 41$ & 0.542 \\
\hline Global burned BSA $<40 \% / \geq 40 \%$ & $0 / 11$ & $2 / 87$ & 0.616 \\
\hline Third-degree burned BSA <20\%/ $\geq 20 \%$ & $0 / 11$ & $2 / 87$ & 0.616 \\
\hline APACHE II on admission to ICU $<15 / \geq 15$ & $9 / 2$ & $64 / 25$ & 0.485 \\
\hline Mean number of operations $\leq 2 />2$ & $9 / 2$ & $29 / 60$ & 0.002 \\
\hline Initiation of nutritional support $\leq 24 \mathrm{~h} />24 \mathrm{~h}$ & $2 / 9$ & $14 / 75$ & 0.834 \\
\hline Initiation of nutritional support $\leq 48 \mathrm{~h} />48 \mathrm{~h}$ & $4 / 7$ & $44 / 45$ & 0.413 \\
\hline Initiation of $\mathrm{EN} \leq 24 \mathrm{~h} />24 \mathrm{~h}$ & $2 / 9$ & $14 / 75$ & 0.834 \\
\hline Initiation of $E N \leq 48 \mathrm{~h} />48 \mathrm{~h}$ & $4 / 7$ & $41 / 48$ & 0.542 \\
\hline Energy content in the first week ( $\mathrm{kcal} / \mathrm{kg}$ per $\mathrm{d}) \leq 30 />30^{*}$ & $5 / 6$ & $51 / 38$ & 0.455 \\
\hline Energy content within 2 weeks (kcal/kg per d) $\leq 30 />30^{*}$ & $8 / 3$ & $31 / 58$ & 0.015 \\
\hline Use of glutamine, yes/no & $7 / 4$ & $65 / 24$ & 0.513 \\
\hline Use of $n-3$ fatty acids, yes/no & $4 / 7$ & $29 / 60$ & 0.801 \\
\hline Use of growth hormone, yes/no & $6 / 5$ & $30 / 59$ & 0.174 \\
\hline Septic shock, yes/no & $9 / 2$ & $18 / 71$ & 0.000 \\
\hline Energy deficit $(\mathrm{kcal} / \mathrm{kg}$ per $\mathrm{d})>20 /<20^{*}$ & $9 / 2$ & $45 / 44$ & 0.050 \\
\hline Protein deficit $(\mathrm{g} / \mathrm{kg}$ per $\mathrm{d})>0.8 /<0.8$ & $10 / 1$ & $48 / 41$ & 0.019 \\
\hline Feeding route gastric/post-pyloric & $6 / 5$ & $66 / 23$ & 0.172 \\
\hline Nutrition tolerance, yes/no & $3 / 8$ & $65 / 24$ & 0.002 \\
\hline
\end{tabular}

BSA, body surface area; APACHE II, Acute Physiology and Chronic Health Evaluation II; ICU, intensive care unit; EN, enteral nutrition.

* To convert kcal to $\mathrm{kJ}$, multiply by $4 \cdot 184$.

including severity of burn, the surgical amount, septic shock, energy and protein deficit, nutrition intolerance, initiation of nutritional support, initiation of EN and ratios of EN providing energy in nutrition multiple regression analysis, it was demonstrated that EN providing $<30 \%$ energy in nutrition and septic shock were the independent risk factors for mortality (OR 5.2; 95\% CI 1.026, 11.682; $P=0 \cdot 042$; OR 6.5; $95 \%$ CI 0.848, 32.156; $P=0 \cdot 031)$.

\section{Discussion}

Data on nutrition support and feeding practices in severe burns patients are scarce. This study, to our knowledge, is the largest in severe burns in China and possibly anywhere else as well. One hundred critically ill patients with severe burns were presented in this study. The consistence of the underlying medical conditions, including the aetiology, injury onset and treatment of all these patients reduced the influence of interference factors. The findings showed that EN can be initiated early in majority of severe burn patients, and post-pyloric feeding is more beneficial than gastric feeding in EN tolerance and energy supplement. Many patients developed EN feeding intolerance, and nearly $90 \%$ patients needed PN supplementation. It is difficult for severe burn patients to obtain adequate feeding, especially in the early stage of the disease. More than 2 weeks of underfeeding may be harmful to recovery.

Nutritional therapy plays an indisputable role for critically ill burn patients from the early start of the initial resuscitation ${ }^{(16)}$. It stimulates mucosal blood flow and maintains gut barrier function and mucosal integrity ${ }^{(17)}$. In our study, the enteral route was the first choice for feeding, in accordance with the guideline. Nevertheless, in our cohort, severe burn injury resulted in gastrointestinal dysfunction; so PN was an alternative or combined approach in almost $90 \%$ of the patients. The majority of our patients initiated nutrition within $72 \mathrm{~h}$ after burn injury, but only sixteen patients began to be fed within $24 \mathrm{~h}$. It differs from some previous studies, in which the majority patients had been fed within $24 \mathrm{~h}^{(18,19)}$. Delayed feeding may due to inadequate medical staff, prolonged triage and transport, the severity of injury and haemodynamic instability.

Feeding intolerance is a common problem in critical burn patients ${ }^{(13)}$. A high rate (32\%) of feeding intolerance was noted in our study, despite the early use of prokinetics in $90 \%$ of the patients. It was similar to Mentec's study ${ }^{(20)}$. Risk factors for enteral feeding intolerance in burn patients include severity scores (APACHE II, simplified acute physiology score II, sequential organ failure assessment), acidosis and electrolyte 
disorders, sedation, use of catecholamines and prone position etc $^{(21)}$. All the risk factors were particularly prevalent in our study patients. In our study, the mean duration of enteral feeding intolerance was 4.7 (SD 3.5) $\mathrm{d}$ which is longer than that in Lavrentieva's report ${ }^{(22)}$. Severity of injury therefore possibly may be associated with an increased prevalence of delayed gastric emptying and feeding intolerance. In addition, a significantly higher incidence of EN intolerance was observed in patients fed total protein formula, fed with a volume above $1500 \mathrm{ml} / \mathrm{d}$ and with septic shock. These observations indicate that both the type and the amount of the EN formula are worthy of attention.

The prevalence of feeding interruption mainly due to adverse events in feeding and perioperative fasting (median interval of 3 d) caused underfeeding in our study. PN was therefore supplemented, which led to hyperglycaemia and liver dysfunction in proportion to energy supply in most of the patients in the first month. Consequently, almost all the patients in our study were notably underfed at the early stage. This is comparable to the results in other non-burn critically ill patients.

Underfeeding should be avoided, considering the correlations between energy and protein deficits and the 28- $\mathrm{d}$ mortality. Potentially available strategies include continuous instead of bolus feeding, higher threshold of GRV for feeding reduction and post-pyloric feeding according to previous studies in cohorts of critically ill patients. Being consistent with the study by Deane et $a l .^{(23)}$, we found that the energy and protein deficits decreased after changing the intra-gastric feeding with post-pyloric delivery because of the gastric intolerance in some patients. Unfortunately, the timing of EN initiation did not affect the 28-d mortality in our study. The possible reasons were the delayed start of EN in most patients and the extreme severity of burn injury. These may also be the key factors affecting patient recovery.

This study has its limitations. Conditions did not allow us to measure the energy expenditure during the study, and the sample size is limited. Since the majority of the population were young to middle-age adults, sedated and analgesic, it may not be possible to exactly match the clinical characteristics of all the population. As a result, our observations may not be fully consistent with various institutional populations.

In conclusion, in our cohort, EN can be initiated early in severe burn patients. Majority of patients were fed by EN supplemented with PN. Post-pyloric feeding was beneficial to improving the tolerance of EN. It is difficult for severe burn patients to obtain adequate feeding, especially in the early stage of the disease. More than 2 weeks of underfeeding may be harmful to recovery.

\section{Acknowledgements}

This study was fully sponsored by the grant of the Special Funds of Jiangsu Provincial Commission of Health and Family Planning of China (H201465) and the grant of the Key Medical Disciplines of Jiangsu Province (ZDXKA2016025). Role of the sponsor: design and conduct of the study, preparation and approval of our manuscript.
F. G., Y. X. and H. Q. had full access to all the data in the study and take responsibility for the integrity of the data and the accuracy of the data analysis. Study concept and design: F. G., H. Q. Acquisition of data: F. G., H. Z., J. W., Y. H., G. L., Y. W., H. Z., J. J., F. Z., L. L., W. L., Y. Y. Analysis and interpretation of data: F. G., H. Z. Statistical analysis and drafting of the manuscript: F. G., H. Z., Y. X. Critical revision of the manuscript for important intellectual content: Y. Y., Y. X., H. Q. Study supervision: H. Q.

The authors declare that there are no conflicts of interest.

\section{References}

1. Peck MD (2011) Epidemiology of burns throughout the world. Part I: distribution and risk factors. Burns 37, 1087-1100.

2. Wassermann D (2002) Criteria for burn severity. Epidemiology, prevention, organization of management. Pathol Biol 50, 65-73

3. Williams FN, Jeschke MG, Chinkes DL, et al. (2009) Modulation of the hypermetabolic response to trauma: temperature, nutrition, and drugs. J Am Coll Surg 208, 489-502.

4. Cunningham JJ (2009) Factors contributing to increase energy expenditure in thermal injury: a review of studies employing indirect calorimetry. J Parenter Enteral Nutr 14, 649-656.

5. Deitch EA (1990) Intestinal permeability is increased in burn patients shortly after injury. Surgery 107, 411-416.

6. Shields BA, Doty KA, Chung KK, et al. (2013) Determination of resting energy expenditure after severe burn. J Burn Care Res 34, e22-e28.

7. Rousseau AF, Losser MR, Ichai C, et al. (2013) ESPEN endorsed recommendations: nutritional therapy in major burns. Clin Nutr 32, 497-502.

8. Lam NN, Tien NG \& Khoa CM (2008) Early enteral feeding for burned patients: an effective method which should be encouraged in developing countries. Burns 34, 192-196.

9. Chiarelli A, Enzi G, Casadei A, et al. (1990) Very early nutrition supplementation in burned patients. Am J Clin Nutr $\mathbf{5 1}$, 1035-1039.

10. Venter M, Rode H, Sive A, et al. (2007) Enteral resuscitation and early enteral feeding in children with major burnseeffect on McFarlane response to stress. Burns 33, 464-471.

11. Pancorbo-Hidalgo PL, García-Fernandez FP \& Ramírez-Pérez C (2001) Complications associated with enteral nutrition by nasogastric tube in an internal medicine unit. J Clin Nurs 10, 482-490.

12. Beaux De, Chapman M, Fraser R, et al. (2001) Enteral nutrition incritically ill: a prospective survey Australian intensive care unit. Anaesth Intensive Care 29, 619-622.

13. Sudenis T, Hall K \& Cartotto R (2015) Enteral nutrition: what the dietitian prescribes is not what the burn patient gets!. J Burn Care Res 36, 297-305.

14. Sallam HS, Oliveira HM, Liu S, et al. (2010) Mechanisms of burn-induced impairment in gastric slow waves and emptying in rats. Am J Physiol Regul Integr Comp Physiol 29, R298-R305.

15. Montgomery AB, Stager MA, Carrico CJ, et al. (1985) Causes of mortality in patients with the adult respiratory distress syndrome. Am Rev Respir Dis 132, 485-489.

16. Rodriguez NA, Jeschke MG, Williams FN, et al. (2011) Nutrition in burns: Galveston contributions. J Parenter Enteral Nutr 35, 704-714.

17. Montejo JC (1999) Enteral nutrition-related gastrointestinal complications in critically ill patients: a multicenter study. The 
Nutritional and Metabolic Working Group of the Spanish Society of Intensive Care Medicine and Coronary Units. Crit Care Med 27, 1447-1453.

18. Holt B, Graves C, Faraklas I, et al. (2012) Compliance with nutrition support guidelines in acutely burned patients. Burns $\mathbf{3 8}$, 645-649.

19. Czapran A, Headdon W, Deane AM, et al. (2015) International observational study of nutritional support in mechanically ventilated patients following burn injury. Burns 25, 761-772.

20. Mentec H, Dupont H, Bocchetti M, et al. (2001) Upper digestive intolerance during enteral nutrition in critically ill patients: frequency, risk factors, and complications. Crit Care Med 29, 1955-1961.

21. Ukleja A (2010) Altered GI motility in critically Ill patients: current understanding of pathophysiology, clinical impact, and diagnostic approach. Nutr Clin Pract 25, 16-25.

22. Lavrentieva A, Kontakiotis T \& Bitzani M (2014) Enteral nutrition intolerance in critically ill septic burn patients. J Burn Care Res 35, 313-318.

23. Deane A, Chapman MJ, Fraser RJ, et al. (2007) Mechanisms underlying feed intolerance in the critically ill: implications for treatment. World J Gastroenterol 13, 3909-3917. 